\title{
Canopy Photosynthesis of Maize-Soybean Intercropping System
}

\author{
Hideki SUGIMOTO*, Yonny KOESMARYONO** and Yukiyo NISHII-MIYAHARA* \\ * Faculty of Agriculture, Ehime University, Tarumi, Matsuyama, 790-8566 Japan \\ **Faculty of Mathematics and Natural Sciences, Bogor Agricultural University, Bogor, 16143 Indonesia
}

\begin{abstract}
The combination of $C_{4}$ crops and $C_{3}$ crops under intercropping is generally profitable because $C_{4}$ crops are photosynthetically-light unsaturated in comparison with $C_{3}$ crops that are photosynthetically-light saturated. The purpose of this study is to characterize the canopy photosynthesis of the maize-soybean intercropping system.

Monoculture plots of maize and soybeans, and intercropping plots at high and low densities of maize sown together with soybeans were prepared. The canopy photosynthesis of each plot was measured at the tasseling stage of the maize and at the pod-filling stage of the soybeans around noon on sunny days by means of a closed chamber system. The diurnal canopy photosynthesis of the soybeans in each plot was measured.

The canopy photosynthetic rate (Pn-canopy) of the high-density plot showed $64.0 \mu \mathrm{mol} \mathrm{CO}_{2} \mathrm{~m}^{-2} \mathrm{~s}^{-1}$, the highest, and that of the low-density plot was the lowest. The Pn-canopies of the maize and soybean monoculture were almost equal. Respiration rate was higher in the plots of the high-density and maize monoculture in proportion to total dry weight. The extinction coefficient $(K)$ of the soybean monoculture plot showed the largest value $(K=0.849)$ and the maize monoculture showed the lowest $(K=0.494)$. The $K$ value of the low-density plot was lower than that of the high-density plot and close to the maize monoculture plot.

The canopy photosynthesis of the soybeans in each plot was compared. The diurnal change in Pn-plant of the low-density plot was almost equal to that of the monoculture; however, due to irradiance interception by maize plants, the Pn-plant of the high-density plot was low throughout the day.
\end{abstract}

Key words: Canopy, Extinction coefficient, Intercropping, Photosynthesis.

\section{Introduction}

In tropical countries, traditional agricultural systems are based on crops grown in mixtures (Willey and Osiru, 1972; Baldy and Stigter, 1997). The possible reason for this system is that intercropping allows a more efficient use of environmental resources such as sun radiation, soil minerals, water, and time (Baldy and Stigter, 1997).

To effectively use sunlight energy, the combination of crops with differing vertical distributions of leaves is well adopted in intercropping. The combination of $\mathrm{C}_{4}$ crops such as maize and sorghum and $C_{3}$ crops such as soybean and mungbean under intercropping is generally profitable because $\mathrm{C}_{4}$ crops are photosynthetically-light unsaturated in comparison with $\mathrm{C}_{3}$ crops which are photosynthetically-light saturated.

Johnson et al. (1989) presented a model of photosynthesis in monocultures and mixtures. Hirota $e t$ al. (1995) measured single leaf photosynthesis under maize-mungbean intercropping; however, few data are available regarding canopy photosynthesis under intercropping. Thus, the purpose of this study is to characterize the canopy photosynthesis of the maize-soybean intercropping system.

\section{Materials and Methods}

\subsection{Plant materials}

Field experiments were conducted at the experimental field of Ehime University, Matsuyama, consisting of alluvial-clay loam soil. Maize (Zea mays L. cv. Pioneer 3470) and soybean (Glycine $\max (\mathrm{L}$.) Merr cv. Fukuyutaka) seeds were sown on July 15, 1996 in north-south oriented rows. Prior to sowing, fertilizer was applied at the rate of 30,100 , and $100 \mathrm{~kg}$ $\mathrm{ha}^{-1}$ of $\mathrm{N}, \mathrm{P}_{2} \mathrm{O}_{5}$ and $\mathrm{K}_{2} \mathrm{O}$, respectively. Monoculture plots of maize and soybeans at each crop standard density, and intercropping plots at two densities of maize sown together with soybean were prepared. The plants were sown under four planting systems, viz: the intercropping of maize (2.67 plants $\mathrm{m}^{-2}$ ) and soybeans $\left(5.33\right.$ plants $\left.\mathrm{m}^{-2}\right)$ as a high-density plot, the intercropping of maize (1.33 plants $\left.\mathrm{m}^{-2}\right)$ and soybeans (5.33 plants $\mathrm{m}^{-2}$ ) as a low-density plot, a maize monoculture plot (5.33 plants $\mathrm{m}^{-2}$ ), and a soybean monoculture plot ( 10.67 plants $\left.\mathrm{m}^{-2}\right)$. Each plot was assigned $9 \times 10 \mathrm{~m}^{2}$ in a randomized complete design with two replications.

\subsection{Measurement of canopy photosynthesis and} respiration

The canopy photosynthesis and respiration of each plot was measured by a closed chamber system (Sugimoto and Koesmaryono, 2001) at the tasseling stage of the maize and at the pod-filling stage of the soybeans around noon on sunny days in the middle of

Accepted on November 24, 2004 
Table 1. Plant height, top dry weight and leaf area index (LAI) of measured plants.

\begin{tabular}{|c|c|c|c|c|c|c|c|c|}
\hline \multirow{2}{*}{ Treatment } & \multicolumn{2}{|c|}{ Plant height (cm) } & \multicolumn{3}{|c|}{ Dry weight $\left(\mathrm{g} \mathrm{m}^{-2}\right)$} & \multicolumn{3}{|c|}{ LAI } \\
\hline & Maize & Soybean & Maize & Soybean & Total & Maize & Soybean & Total \\
\hline High-density & 225 & 118 & 449.9 & 218.4 & 668.3 & 1.67 & 2.95 & 3.62 \\
\hline Low-density & 218 & 110 & 245.4 & 255.7 & 501.1 & 0.86 & 3.37 & 4.23 \\
\hline Maize monoculture & 228 & - & 665.2 & - & 665.2 & 3.61 & - & 3.61 \\
\hline Soybean monoculture & - & 112 & - & 535.4 & 535.4 & - & 6.27 & 6.27 \\
\hline
\end{tabular}

September.

Three aluminum-framed chambers covered with a transparent vinyl film were prepared for the measurement of maize and soybean plants in the same chamber $(160 \mathrm{~cm} \times 80 \mathrm{~cm} \times 180 \mathrm{~cm}$ height $)$, for maize plants only ( $90 \mathrm{~cm} \times 80 \mathrm{~cm} \times 180 \mathrm{~cm}$ height), and for soybean plants only $(90 \mathrm{~cm} \times 60 \mathrm{~cm} \times 90 \mathrm{~cm}$ height). Each chamber was set on a wood-framed base $(30 \mathrm{~cm}$ height) covered with a transparent vinyl film. Three fans were used to circulate air in the chamber, and air temperature was controlled by passing tap water through a cooling system installed in the chamber. The air temperature in the chamber varied from 28 to $32{ }^{\circ} \mathrm{C}$ according to the outside temperature. Due to dehumidification by the cooling system, dew did not form inside the chamber wall. An infrared gas analyzer (ZFP5, Fuji Electric, Japan) set in the chamber was used to determine the change in $\mathrm{CO}_{2}$ concentration per unit of time.

Canopy photosynthetic rate (Pn-canopy) was determined based on the volume of the chamber (volume of plants and equipments was deducted) and the decrease in $\mathrm{CO}_{2}$ concentration during the measurement period. Exhaust $\mathrm{CO}_{2}$ was supplied by gas cylinder into the chamber. Dark respiration was determined by covering the chamber with a black cotton sheet for about ten minutes.

Photosynthetically active radiation (PAR) was monitored using a quantum sensor (LI-190SB, LI-COR, U. S. A.). Air and soil temperatures were recorded using copper-constantan thermocouples. The PAR distribution within the canopy was measured using a line quantum sensor (LI-191SB, LI-COR, U. S.
A.) from the top to the bottom at $20 \mathrm{~cm}$ intervals.

Immediately after the measurement of respiration, plants were clipped in accordance with the stratified clip method from the top to the bottom at $20 \mathrm{~cm}$ intervals. Soil respiration was determined after the plants were removed. Clipped plants were then separated into leaves and other parts. Leaf area was measured with an area meter (AAM-7, Hayashi Denko, Japan). Plant samples were dried at $85{ }^{\circ} \mathrm{C}$ for 3 days in an oven, then weighed.

\section{Results}

\subsection{Plant height, top dry weight and leaf area index (LAI)}

The plant height, top dry weight and leaf area index (LAI) of the measured plants are shown in Table 1.The plant height of the maize and soybeans showed little respective difference between plots. The total top dry weight of the high-density and maize monoculture plots was higher than those of the low-density and soybean monoculture plots. The LAI in the soybean monoculture plot showed 6.27, the highest, and that in the maize monoculture plot showed the lowest at 3.61. 3.2 Photosynthetic and respiration rate

The photosynthetic and respiration rates are shown in Table 2. The total Pn-canopy of the high-density plot showed $64.0 \mu \mathrm{mol} \mathrm{CO}_{2} \mathrm{~m}^{-2} \mathrm{~s}^{-1}$, the highest, and that of the low-density plot was the lowest. The Pn-canopy of the maize and soybean monoculture was almost equal.

The contribution ratios of maize and soybeans to total Pn-canopy in the high-density plot were $61 \%$ and

Table 2. Photosyntetic and respiration rate.

\begin{tabular}{|c|c|c|c|c|c|c|c|c|}
\hline \multirow{2}{*}{ Treatment } & \multicolumn{3}{|c|}{ Pn-canopy ${ }^{1)}$} & \multicolumn{2}{|c|}{ Pn-plant ${ }^{2)}$} & \multicolumn{2}{|c|}{ Pn-leaf ${ }^{3}$} & \multirow{2}{*}{$\begin{array}{c}\text { Respiration }^{4)} \\
\text { Total } \\
\end{array}$} \\
\hline & Maize & Soybean & Total & Maize & Soybean & Maize & Soybean & \\
\hline High-density & $39.3(61)$ & 24.7 (39) & 64.0 & 14.7 & 4.6 & 22.9 & 8.4 & 14.4 \\
\hline Low-density & $23.9(44)$ & $30.5(56)$ & 54.4 & 17.9 & 5.7 & 28.6 & 9.1 & 9.3 \\
\hline Maize monoculture & $58.5(100)$ & - & 58.5 & 11.0 & - & 16.2 & - & 13.5 \\
\hline Soybean monoculture & - & $57.8(100)$ & 57.8 & - & 5.4 & - & 9.2 & 9.4 \\
\hline
\end{tabular}

${ }^{1)}$ : Photosynthetic rate per unit land area $\left(\mu \mathrm{mol} \mathrm{CO} \mathrm{Cm}^{-2} \mathrm{~s}^{-1}\right){ }^{2)}$ : Photosynthetic rate per plant $\left(\mu \mathrm{mol} \mathrm{CO}_{2}\right.$ plant $\left.^{-1} \mathrm{~s}^{-1}\right)$.

${ }^{3)}$ : Photosynthetic rate per unit leaf area $\left(\mu \mathrm{mol} \mathrm{CO} \mathrm{Cm}^{-2} \mathrm{~s}^{-1}\right)$. ${ }^{4)}$ : Respiration rate per unit land area $\left(\mu \mathrm{mol} \mathrm{CO}_{2} \mathrm{~m}^{-2} \mathrm{~s}^{-1}\right)$.

Numerals in the parenthesis are percentage to the total Pn-canopy. 

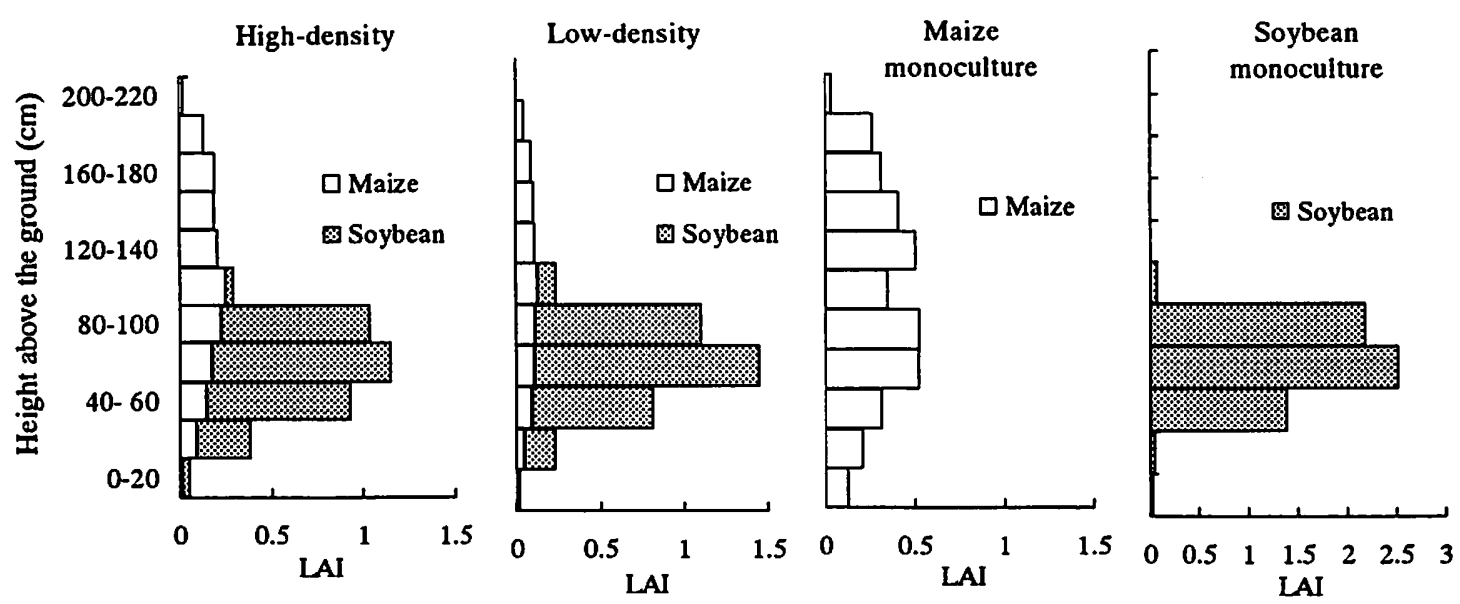

Fig. 1. Canopy structure.

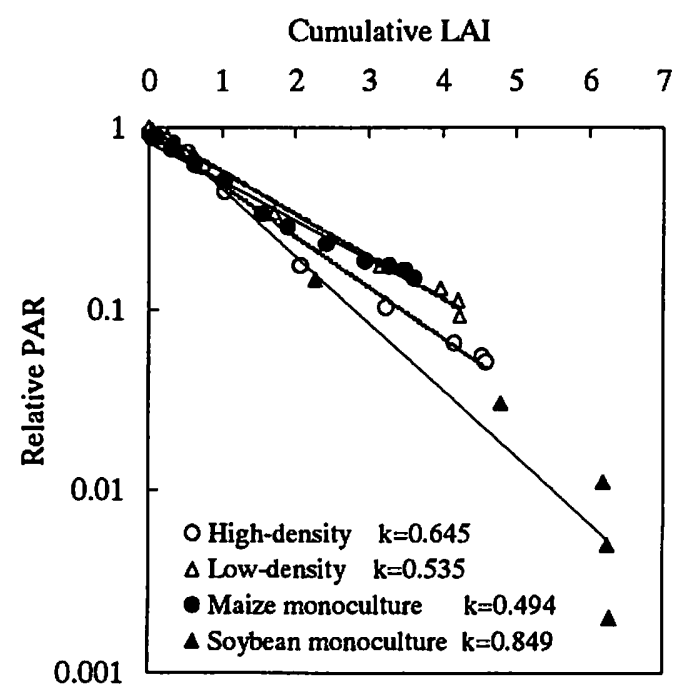

Fig. 2. Relationship between $L A I$ and relative PAR. k: Extinction coeffient.

$39 \%$, respectively. Those in the low-density plot were $44 \%$ and $56 \%$, respectively.

The photosynthetic rate per plant (Pn-plant) of maize in the low-density plot was the highest at $17.9 \mu$ mol $\mathrm{CO}_{2}$ plant $^{-1} \mathrm{~s}^{-1}$, and that of soybeans in the high-density plot was the lowest. The photosynthetic rate per unit leaf area (Pn-leaf) of maize was higher than that of soybeans in all plots. The Pn-leaf of maize in the low-density plot showed $28.6 \mu \mathrm{mol} \mathrm{CO} \mathrm{Cm}^{-2} \mathrm{~s}^{-1}$, the highest, and that of the soybeans in the high-density-plot showed the lowest, $8.4 \mu \mathrm{mol} \mathrm{CO}_{2}$ $\mathrm{m}^{-2} \mathrm{~s}^{-1}$.

Respiration rate was higher in the high-density and maize monoculture plots in proportion to total dry weight (Table 1).

\subsection{Canopy structure and extinction coefficient $(K)$}

The canopy structure at the measurement period of photosynthetic rate is shown in Fig. 1. Soybean leaves were located below half the height of the intercrop canopy. The maximum LAI was found at the layer $60-80 \mathrm{~cm}$ above the ground, and was 1.15 for the

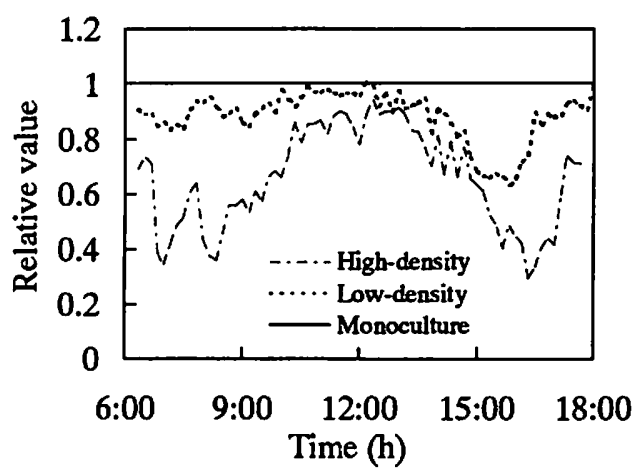

Fig. 3. Relative PAR over the soybean canopy.

high-density plot and 1.51 for the low-density plot, respectively.

Fig. 2 shows the relationship between the cumulative LAI obtained by the accumulation of the leaf area values shown in Fig. 1 from the top layer to each layer and the relative light intensity (PAR) in the canopy. The extinction coefficient $(K)$ was calculated using the following equation (Monsi and Saeki, 1953):

$$
I=I_{0} e^{-K F}
$$

where $I$ represents the light intensity under the leaf canopy, $I_{0}$, the incident light intensity, and $F$ the leaf area index. The soybean monoculture plot showed the largest value of $K=0.849$ while the maize monoculture plot showed the lowest $(K=0.494)$. The $K$ value of the low-density plot was lower than that of the high-density plot and close to the maize monoculture plot.

\subsection{Relative PAR over the soybean canopy}

The PAR in the intercropping plots relative to the monoculture plot over the soybean canopy is shown in Fig. 3. The relative PAR in the high-density plot was remarkably low before AM10:00 and after PM14:00.

\subsection{Diurnal changes of soybean Pn-canopy}

The diurnal change in Pn-plant (A) and Pn-canopy (B) of each soybean plot is shown in Fig. 4. The 

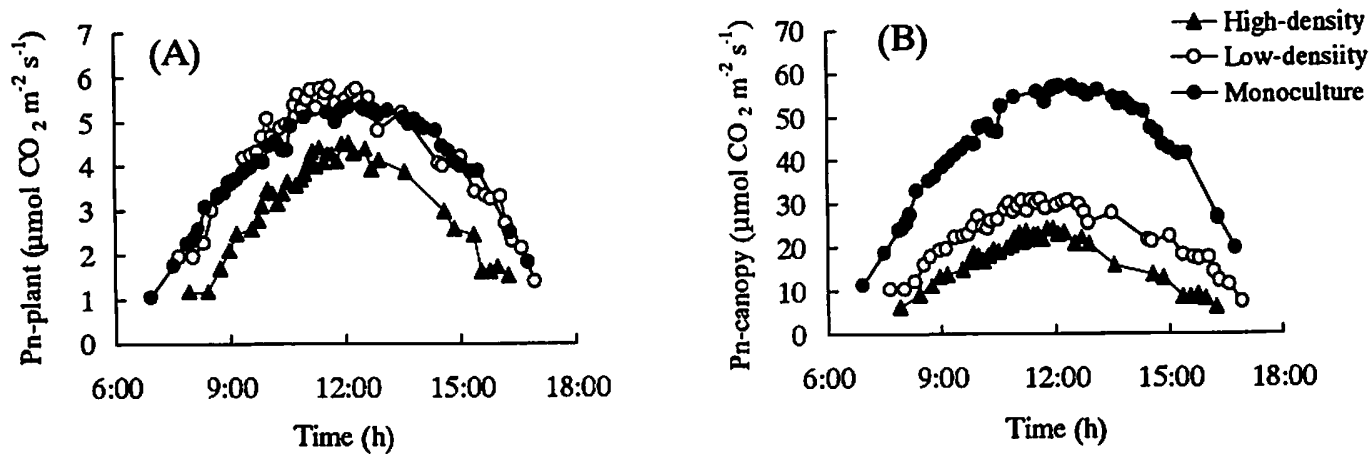

Fig. 4. Diumal changes of soybean Pn-plant (A), Pn-canopy (B).

diurnal change in Pn-plant of the low-density plot was seen to be almost equal to that of the monoculture plot; however, due to irradiance interception by the maize plants, Pn-plant of the high-density plot was low throughout the day. The Pn-canopy of the low-density plot was about a half that of the monoculture plot and that of the high-density plot was about $80 \%$ of the low-density plot throughout the day.

\section{Discussion}

Eagles and Wilson (1982) tabulated the results of canopy photosynthesis measurements. The highest rates for each of eleven $C_{3}$ species in their survey ranged from 19.6 to $79.5 \mu \mathrm{mol} \mathrm{CO}_{2} \mathrm{~m}^{-2} \mathrm{~s}^{-1}$, while those for the four $\mathrm{C}_{4}$ species ranged from 31.5 to 90.7 $\mu \mathrm{mol} \mathrm{CO} \mathrm{m}^{-2} \mathrm{~s}^{-1}$. Kanemasu and Hiebsch (1975) compared to the rates for sorghum, wheat, and soybean canopies. Sorghum reached $63 \mu \mathrm{mol} \mathrm{CO}_{2} \mathrm{~m}^{-2} \mathrm{~s}^{-1}$; however, the wheat and soybean crops did not exceed $28 \mu \mathrm{mol} \mathrm{CO} \mathrm{Cm}^{-2} \mathrm{~s}^{-1}$. In the current experiments, the Pn-canopy of the maize monoculture was almost equal to the mean value of the $\mathrm{C}_{4}$ plants and sorghum as indicated here; however, that of the soybean monoculture was relatively high.

The light conditions in the intercropping canopy are an important factor for evaluating the benefit of Pn-canopy in this system. The $K$ value is a suitable indicator of the canopy's effective use of irradiance. The effective canopy extinction coefficient $\left(K_{c}\right)$ was calculated using the following equation (Johonson $e t$ al., 1989):

$$
K_{e}=\left(K_{m} L_{m}+K_{s} L_{s}\right) /\left(L_{m}+L_{s}\right)
$$

where $K_{m}$ and $K_{s}$ represents the extinction coefficients of maize and soybeans, respectively, and $L_{m}$ and $L_{s}$ are the cumulative LAI of maize and soybeans, respectively. The $K_{e}$ values of the high and low-density plots were 0.721 and 0.711 , respectively. The $K$ values in this experiment were lower than the $K_{c}$ values calculated by equation 2 . These results indicate that the intercropping system had developed a canopy structure for light interception.

Maize leaves located in the upper and middle layer of the intercrop canopy can utilize light energy efficiently because of $\mathrm{C}_{4}$ photosynthesis, while soybean leaves located in the lower layer receive an insufficient amount of light energy, but utilize it efficiently because the leaves expand horizontally. The habitat segregation by height and the low $K$ value of the high-density plot seemed to result in higher Pn-canopy, and also higher dry matter production and higher yield. However, the Pn-canopy of the low-density plot was low, presumably because the maize LAI was too low.

\section{References}

Baldy, C. and Stigter, C. J., 1997: Agrometeorology of multiple cropping in warm climates. IRNA, Paris Cedex, 237 pp.

Eagles, C. F. and Wilson, D., 1982: Photosynthetic efficiency and plant productivity. In Handbook of Agricultural Productivity. (ed. by Rechigl, M.), Vol 1. CRC Press. Boca Raton, Florida, pp. 213-247.

Hirota, O. Hashem, A. and Hamid, A., 1995: Yield, photosynthesis and canopy structure of maize-mungbean intercropping system. Jpn. J. Trop. Agr., 39, 168-176.

Johnson, I. R., Parsons, A. J. and Ludlow, M. M., 1989: Modeling photosynthesis in monoculture and mixture. Aust. J. Physiol., 16, 501-516.

Kanemasu, E. T. and Hiebusch, C. K, 1975: Net carbon dioxide exchange of wheat, sorghum and soybean. Can. J. Bot., 53, 382-389.

Monsi, M. and Saeki, T., 1953: On the light factor in the plant community and its meaning for the biomass production. Jpn. J. Bot., 14, 22-52.

Sugimoto, H. and Koesmaryono, Y., 2001: Photosynthesis of buckwheat population under field conditions with special reference to planting density. Environ. Control in Biol. 39:175-182.

Willey, R.W. and Osiru, D. S. O., 1972: Studies on mixtures of maize and beans (Phaseolus vulgaris) with particular reference to plant population. J. Agric. Sci. Camb., 79, 517-529. 